\title{
Response of earthworm coelomocytes and catalase to pentanone and hexanone: A revelation of the toxicity of conventional solvents at the cellular and molecular level
}

\author{
Xiangxiang Li \\ Shandong University \\ Meifei Li \\ Shandong University \\ Ning Sun \\ Shandong University
}

Falin $\mathrm{He}$

Shandong University

Shanshan Chu

Shandong University

Wansong Zong

Shandong Normal University

Qigui Niu

Shandong University

Rutao Liu ( $\nabla$ rutaoliu@sdu.edu.cn )

Shandong University

\section{Research Article}

Keywords: 2-Pentanone, 2-Hexanone, Oxidative stress, Coelomocytes, Catalase

Posted Date: April 23rd, 2021

DOI: https://doi.org/10.21203/rs.3.rs-412019/v1

License: (c) (i) This work is licensed under a Creative Commons Attribution 4.0 International License. Read Full License

Version of Record: A version of this preprint was published at Environmental Science and Pollution Research on February 7th, 2022. See the published version at https://doi.org/10.1007/s11356-022- 
18864-1.

Page $2 / 28$ 


\section{Abstract}

Organic solvents like 2-Pentanone and 2-Hexanone which are widely used in industrial production play an important role in the source of chemical pollution. Based on the current gaps in 2-Pentanone and 2Hexanone cytotoxicity studies, the earthworms in the soil, which are susceptible to solvent leakage and volatilization, were selected as the receptor. The cytotoxicity of 2-Pentanone and 2-Hexanone was revealed by measuring the multiple intracellular indicators of oxidative stress. At the molecular level, changes in the structure and function of antioxidant enzyme catalase (CAT) were characterized in vitro by a variety of spectroscopy methods and molecular docking. The results show that 2-Pentanone and 2Hexanone that induced the accumulation of intracellular reactive oxygen species can eventually decrease the cell viability of coelomocytes, accompanied by the regular changes of antioxidant activity and lipid peroxidation level. In addition, the exposure of 2-Pentanone and 2-Hexanone can shrink the backbone structure of CAT, quench the fluorescence and misfold the secondary structure. The decrease in enzyme activity should be attributed to the structural changes induced by surface binding. This study discussed the toxicological effects and mechanisms of commonly used organic solvents at the cellular and molecular level, which creatively proposed a new combined method.

\section{Introduction}

Organic solvents are widely used in various industries, such as paints, adhesives, degreasing agents, pesticides, cosmetics and cleaning products (Dick 2006, Pedersen et al. 2020). Both 2-Pentanone and 2Hexanone are organic solvents commonly used in industrial production. 2-Pentanone is not only a polar solvent but also a good extractant that has excellent extraction efficiency in extracting aliphatic acids (including acetic acid and propionic acid) (Arce et al. 1995, Bianco et al. 1988, Hashemi et al. 2004). Chen et al. (Chen et al. 2017) used 2-Pentanone to extract cresol from coal gasification wastewater, thus showing good extraction performance. The primary uses for 2-Hexanone involve its application as a solvent in lacquers, which is also a useful solvent for oils, resins, fats, waxes and nitrocellulose (Couri \&Milks 1982). As volatile biomarkers, 2-Pentanone and 2-Hexanone are commonly used to quantitatively evaluate lung cancer, gastric cancer, inflammatory bowel disease and kidney disease (Brůhová Michalčíková et al. 2016, Gopas et al. 2018, Mochalski et al. 2018, Santos et al. 2017, Wang et al. 2017b), increasing the possibility of laboratory exposure.

In the early stage, ketone solvents were considered safer for industrial use (Couri \&Milks 1982), but a series of toxicological experiments showed that the exposure of such industrial solvents would cause great harm to humans and laboratory animals. Hewitt et al. (Hewitt et al. 1980) proved that the degree of liver damage is related to the carbon chain length of ketone solvent. Furthermore, Hewitt et al. (Hewitt et al. 1983) also proved that both 2-Pentanone and 2-Hexanone can enhance liver damage caused by halogenated hydrocarbons such as $\mathrm{CHCl}_{3}$ and $\mathrm{CHCl}$ through liver toxicity measurement experiment in rats. For 2-Pentanone, researchers have produced mixed toxicological research conclusions. Pettersson et al. (Pettersson et al. 2008) experimentally confirmed that 2-Pentanone can inhibit the production of prostaglandins and the activity of the enzyme cyclooxygenase-2 (COX-2) in colon cancer cells (HT-29). 
Therefore, they concluded that 2-Pentanone can be used as a chemopreventive agent for colon cancer, which can provide recommendations for the human diet. For 2-Hexanone, Abdel-Rahman et al. (AbdelRahman et al. 1976) found that the exposure of 2-Hexanone can lead to peripheral neuropathy in humans and laboratory animals. Neurotoxic effects have been observed in workers who have to inhale 2Hexanone over long periods (Zimmermann et al. 1989). Abdel-Rahman et al. (Abdel-Rahman et al. 1978) verified that 2-Hexanone can destroy the pupil response, which can be used as an indicator of solvent exposure in the working environment for workers. In addition, Kelce et al. (Kelce et al. 1990) proved that the administration of 2-Hexanone to adult rats can inhibit the activity of 17a-hydroxylase in the testis, thereby compromising steroidogenic function. Studies by Nakajima et al. (Nakajima et al. 1991) confirmed that 2-Hexanone can not only induce quantitative changes in rat constitutive cytochrome P450 (P450IIE1 and P450IIC11/6), but also affect different types of isoenzymes (P450IIB 1/2).

At present, researchers have done a lot of research on organic solvents (Pedersen et al. 2020) that are listed as carcinogenic substances for humans by the International Agency for Research on Cancer (IARC). What's worrying is that the cellular and molecular toxicity of 2-Pentanone and 2-Hexanone have been studied less and there is currently little attention to the pollution risk of organic solvents to the soil, leading to research progress lagging far behind the increase in exposure routes. Taking into account the possible leakage of organic solvents during production, transportation or use and that soil is often one of the most important receptors when chemical production leaks and pollution occurs, this study selected earthworms whose life activities are in direct contact with the soil as receptors and coelomocytes as target cells to study the exposure hazards of 2-Pentanone and 2-Hexanone.

Oxidative stress is the commonly used indicator to evaluate the cytotoxicity of exogenous pollutants (Cheng et al. 2017, Gao et al. 2020). The specific oxidative stress mechanism is shown in Fig. 1. This stress response derived from the accumulation of reactive oxygen species (ROS) will force the body to form an antioxidant defense system (Jing et al. 2020). Reducing the production and eliminating the generation of ROS are the two lines of defense for organisms (Czarna \&Jarmuszkiewicz 2006). Catalase (CAT) and superoxide dismutase (SOD) as direct antioxidant enzymes are considered to be the second line of defense against oxidative damage (El-Aal 2012, Shukla et al. 2014, Zhao et al. 2019). Transform in the activity of CAT and SOD can disrupt the balance between the intracellular oxidation and antioxidant defense systems, causing excessive accumulation of ROS, increased level of cellular lipid peroxidation, ultimately resulting cell apoptosis (Hao \&Liu 2019). Cell viability, ROS level and malondialdehyde (MDA) content were determined to evaluate the physiological response of the cells when oxidative stress and antioxidant defense systems are in a balanced and unbalanced state. In order to evaluate the antioxidant stress ability of coelomocytes, we measured the activities of SOD, CAT, glutathione (GSH) and total antioxidant capacity (T-AOC) in the cells. In addition, at the molecular level, through the direct interaction of 2-Pentanone and 2-Hexanone with CAT, the activity changes of intracellular antioxidant enzymes under the oxidative stress mechanism can be further responded.

Multiple spectroscopy techniques, enzyme activity determination methods and molecular docking were used to identify the detailed mechanism of the direct binding of CAT with 2-Pentanone and 2-Hexanone. 
This research is expected to provide a method for studying the damage mechanism of ketone organic solvents to humans and experimental animals at the cellular and molecular level and new strategies for inhibiting and treating the damage caused by 2-Pentanone and 2-Hexanone to health.

\section{Materials And Methods 2.1. Chemicals}

2-Pentanone, 2-Hexanone and guaifenesin were obtained from Shanghai Macklin Biochemical Co., Ltd.; Absolute ethanol was purchased from Sinopharm Chemical Reagent Beijing Co., Ltd.; Physiological saline was purchased from Shandong Kelun Pharmaceutical Co., Ltd.; Fetal bovine serum, penicillin mixture and $\mathrm{Na}_{2}$ EDTA were provided by Beijing Solarbio Science \& Technology Co., Ltd.; Phosphate buffered solution (PBS, $0.02 \mathrm{M}, \mathrm{pH}=7.4$ ) and Roswell Park Memorial Institute (RPMI) 1640 medium were purchased from Beijing Maichen Technology Co., Ltd.; Oxidative stress determination kit including SOD and GSH, CCK-8 cell viability assay kit, T-AOC and total protein (TP) assay kit, reactive oxygen species (ROS) and malondialdehyde (MDA) assay kit were bought from Nanjing Jiancheng Institute of Bioengineering. In addition, CAT from bovine liver was gained from Beijing Solarbio Science \& Technology Co., Ltd. The $\mathrm{NaH}_{2} \mathrm{PO}_{4} \cdot 2 \mathrm{H}_{2} \mathrm{O}$ and $\mathrm{Na}_{2} \mathrm{HPO}_{4} \cdot 12 \mathrm{H}_{2} \mathrm{O}$ used to prepare the phosphate buffer $(0.02 \mathrm{M}, \mathrm{pH}=7.4)$ were received from Tianjin Damao Chemical Reagent Factory. All reagents were of analytical grade.

\subsection{Intracellular oxidative stress analysis \\ 2.2.1. Extraction and culture of coelomocytes}

Take out 12 earthworms that have been domesticated for a week, and perform a 24-hour intestinal cleansing. The earthworms were immersed in the coelomocytes extract, which include $5 \%$ absolute ethanol, $95 \%$ normal saline, $2.5 \mathrm{mg} \mathrm{mL}^{-1} \mathrm{Na}_{2}$ EDTA and $10 \mathrm{mg} \mathrm{mL}^{-1}$ guaiacol glycerol ether (Eyambe et al. 1991). After extraction, the cell sap was centrifuged (3500 rpm, $5 \mathrm{~min}$ ) and the supernatant was discarded. Then the precipitate was washed twice with normal saline and transferred to the complete medium (RPMI 1640 medium: bovine serum albumin: penicillin solution = 89:10:1). The following is pipetting the cell liquid evenly and diluting it to $10^{5}$ cells of $1 \mathrm{~mL}$. After the dilution was completed, $90 \mu \mathrm{L}$ of cell sap was transferred to the well plate, and $10 \mu \mathrm{L}$ of 2-Pentanone and 2-Hexanone at concentrations of $0,0.1,1,5$ and $10 \mathrm{mM}$ were added to each well. In addition, the cell viability experiment set up blank control wells and reference wells. The blank control wells contained $10 \mu \mathrm{L}$ of physiological saline and 90 $\mu \mathrm{L}$ of cell suspension. And $10 \mu \mathrm{L}$ of different concentration ligands solution and $90 \mu \mathrm{L}$ of complete medium were added to the reference wells. After the preparation was completed, the well plate was incubated at $20^{\circ} \mathrm{C}$ without carbon dioxide for $24 \mathrm{~h}$.

\subsubsection{Determination of cell viability}


The coelomocytes culture plate was taken out and $10 \mu \mathrm{L}$ CCK-8 reagent was added to each well with the multichannel pipette. Then the plates were placed in a cell incubator and left in the dark for two hours. The absorbance of each well was measured by a microplate reader (Infinite 200Pro, Tecan, Switzerland) at a wavelength of $450 \mathrm{~nm}$. The cell viability was calculated using the Eq. (1) (Xu et al. 2019a):

Cell viability $(\%$ control $)=\left[\left(A_{s}-A_{b}\right) /\left(A_{c}-A_{b}\right)\right] \times 100 \%(1)$

Where $A_{S}$ is the OD value of the experimental group; the OD value of the reference group is represented by $A_{b}$; and $A_{c}$ represents the $O D$ value of the control group. The experimental results are characterized by the relative viability value which is the data of the experimental group divided by the control group.

\subsubsection{Measurement of intracellular ROS level}

After the poisoning work was completed, the number of living cells in each sample was determined by the Countess $\otimes$ automatic cell counter (Thermo Fisher Scientific, Waltham, MA, USA). Then the cells were mixed into a PBS solution containing $10 \mu \mathrm{M} \mathrm{DCFH-DA} \mathrm{probe,} \mathrm{and} \mathrm{then} \mathrm{incubated} \mathrm{at} 37^{\circ} \mathrm{C}$ for one hour in the dark. The sample was centrifuged at $3500 \mathrm{rpm}$ for $5 \mathrm{~min}$ and resuspended in PBS solution. The fluorescence intensity was measured with the microplate reader at the excitation and emission wavelength of 485 and $538 \mathrm{~nm}$, respectively. ROS levels per 10,000 living cells were obtained and compared with blank controls.

\subsubsection{Detection of SOD and CAT activity, and GSH content}

The cultured cells were taken out and sonicated 20 times in frozen D-Hanks buffer ( 5 s each time), and then centrifuged at $5000 \mathrm{rpm}$ for $5 \mathrm{~min}$ at $4^{\circ} \mathrm{C}$. After standing for 5 minutes at room temperature, the supernatant was taken to determine the intracellular SOD and CAT activities. The SOD activity was determined by xanthine oxidase method (Sun et al. 2020). The superoxide anion radical $\left(\mathrm{O}_{2}{ }^{-}\right)$produced by the xanthine oxidase reaction system will oxidize hydroxylamine to nitrite, which can appear purple under the action of the developer. The SOD contained in the sample can inhibit $\mathrm{O}_{2}{ }^{-}$, accordingly reducing the absorbance.

The CAT activity was obtained by measuring the rate of decrease in absorbance at $240 \mathrm{~nm}$ (Sun et al. 2014). The measurement sample included $0.2 \mathrm{~mL}$ supernatant and $2.8 \mathrm{~mL} 10 \mathrm{mM} \mathrm{H}_{2} \mathrm{O}_{2}$. Ultrapure water was used as a reference. Based on the results of the change in absorbance at $240 \mathrm{~nm}$ within $3 \mathrm{~min}$, a scatter plot was created, which would be linearly fitted. The experimental results were characterized by relative activity that was set to $100 \%$ of unexposed CAT activity.

Intracellular glutathione (GSH) level were determined by the method provided by the glutathione assay kit. GSH can react with dithiodinitrobenzoic (DTNB) acid to produce the yellow compound that can be used to ascertain the intracellular GSH content (Sun et al. 2020).

\subsubsection{MDA and T-AOC assay at the molecular level}


Determine the content of Intracellular MDA and T-AOC according to the TBA and iron reduction methods. MDA can be condensed with thiobarbituric acid to generate a red product with a maximum absorption peak at $532 \mathrm{~nm}$ (Rafaela et al. 2010). After adding reagents to each sample according to the requirements of the MDA assay kit, the centrifuge tubes containing the sample were placed in $95^{\circ} \mathrm{C}$ water bath for $40 \mathrm{~min}$, taken out and cooled with running water, then centrifuged at 3500-4000 rpm for $10 \mathrm{~min}$, and the supernatant was taken for absorbance measurement. Iron reduction method is used to measure intracellular T-AOC. Antioxidant substances in the body reduce $\mathrm{Fe}^{3+}$ to $\mathrm{Fe}^{2+}$, which can form stable complexes with phenanthrolines. The antioxidant capacity of the system is reflected by colorimetry.

For Chaps. 2.2.2-2.2.4, it is necessary to measure the total protein (TP) content in the cell at the same time as the measurement of each indicator, and compare the results of each indicator on the basis of the same TP amount. The determination of TP content relied on Coomassie Brilliant Blue developer. The 100 $\mu \mathrm{L}$ supernatant was reacted with a chromogenic reagent for $10 \mathrm{~min}$, and the absorbance was determined at $595 \mathrm{~nm}$ with a microplate reader.

\subsection{Analysis of the molecular mechanism of 2-Pentanone and 2-Hexanone interaction with CAT}

\subsubsection{Fluorescence measurements}

The specific parameters of fluorescence spectroscopy commonly used to evaluate the microenvironmental changes of protein aromatic amino acids were set as follows (Zhao et al. 2017): Both the fluorescence and synchronous fluorescence spectrum were measured by F-4600 fluorescence spectrophotometer (Hitachi, Japan). The Photo multiplier tube (PMT) voltage was set to $650 \mathrm{~V}$. The slit width of the excitation and emission wavelengths were set at $5.0 \mathrm{~nm}$. The data interval was set to $0.2 \mathrm{~nm}$ and scanning was performed at a speed of $1200 \mathrm{~nm} \mathrm{~min}{ }^{-1}$. The fluorescence lifetimes of CAT in the absence and presence of 2-Pentanone and 2-Hexanone were measured at $\lambda \mathrm{ex}=280 \mathrm{~nm}$ and $\lambda \mathrm{em}=330$ $\mathrm{nm}$ by the FLS920 fluorescence and steady-state spectrophotometer (Edinburgh, England).

Due to the internal filtering effect (IFE) of CAT and ligands, the fluorescence intensity should be corrected using the following formula. (Sur et al. 1979).

$F_{\text {cor }}=F_{\text {obsd }} 10\left(\mathrm{~A}_{1}+\mathrm{A}_{2}\right) / 2(2)$

where $F_{\text {cor }}$ and $F_{\text {obsd }}$ are the corrected and detected fluorescence intensities, respectively; whereas $A_{1}$ and $A_{2}$ are the absorbance of reaction system at the excitation and emission wavelengths, respectively.

In the fluorescence lifetime experiment, the average fluorescence lifetime $\left(\tau_{A V}\right)$ that can determine the way of fluorescence quenching was calculated by the following equation (Seidel et al. 1996).

$\tau_{A V}=a_{1} \tau_{1}+a_{2} \tau_{2}(3)$ 
where $\tau_{1}$ and $\tau_{2}$ are the double exponential decay fluorescence lifetime values, and $a_{1}$ and $a_{2}$ are the proportions of $\tau_{1}$ and $\tau_{2}$, respectively $\left(a_{1}+a_{2}=1\right)$.

\subsubsection{Research on the changes of CAT conformation}

The Uv-vis absorption spectra reflecting the information of protein skeleton structure were determined by the UV-2450 spectrophotometer (Shimadzu, Kyoto, Japan) (Wang et al. 2019). The wavelength scanning range was $190-500 \mathrm{~nm}$. The data interval and slit width were set at $0.2 \mathrm{~nm}$ and $2.0 \mathrm{~nm}$, respectively, with high scanning speed.

The J-810 circular dichromatograph (Jasco, Japan) was used to reveal circular dichroism (CD) spectra. The parameters are set as follows: scanning wavelength 190-250 nm; The scanning speed was set as $200 \mathrm{~nm} \mathrm{~min}{ }^{-1}$ and a $1 \mathrm{~mm}$ quartz cuvette was utilized. Each spectrum is the average of three consecutive scans. CD Pro software was employed for data analysis of secondary structure content (Xu et al. 2019a).

Resonance light scattering (RLS) is often used to characterize the volume of particles in the system, thus reflecting the aggregation tendency of enzymes (Wang et al. 2017a). F-4600 fluorescence spectrophotometer was used to measure the RLS spectrum. Parameters settings were: PMT $550 \mathrm{~V}$, data interval $0.2 \mathrm{~nm}$, scanning speed $1200 \mathrm{~nm} \mathrm{~min}{ }^{-1}$, excitation and emission slit width $5.0 \mathrm{~nm}$. The scanning range under the excitation wavelength equal to the emission wavelength used in the measurement was $200-600 \mathrm{~nm}$.

\subsubsection{Determinations of CAT activity}

The change of CAT activity is characterized by the change of $\mathrm{H}_{2} \mathrm{O}_{2}$ absorption value at $240 \mathrm{~nm}$. Add 2.8 $\mathrm{mL}$ of $\mathrm{H}_{2} \mathrm{O}_{2}$ solution ( $10 \mathrm{mM}$ ) diluted with phosphate buffer solution and $0.2 \mathrm{~mL}$ of the sample solution to a $10 \mathrm{~mm}$ optical diameter quartz cuvette. The measurement method is the same as Sect. 2.2.4. Three independent repeated experiments were performed.

\subsubsection{Statistical analysis}

Statistical results of Sect. 2.2.2-2.2.5 and 2.3.3 are shown as the mean \pm SEM of three independent experiments. Multiple comparisons of blank control with ligands-treated groups were assessed by ANOVA followed by the Tukey's multiple comparison test.

\section{Results And Discussion}

3.1. Cytotoxicity to coelomocytes of the earthworm induced by 2-Pentanone and 2-Hexanone

\subsubsection{Effect of 2-Pentanone and 2-Hexanone on cell viability}


The cell viability of coelomocytes after being exposed to the ligands was evaluated to reflect the cytotoxicity (Zhao et al. 2019). As shown in Fig. 2(a), with the increase of 2-Pentanone and 2-Hexanone concentration, the cell viability expressed the trend of first increasing and then decreasing. Specifically, the maximum cell viability of 2-Pentanone and 2-Hexanone are $156.19 \%$ and $149.21 \%$. On the contrary but it makes sense that when the ligands concentration reached to $10 \mathrm{mM}$, the cell viability that was significantly inhibited was down to $80.33 \%$ and $60.79 \%$, respectively. The results show that both $2-$ Pentanone and 2-Hexanone will have a great impact on the cell viability. In the concentration range of 0$1 \mathrm{mM}$, the ligands may stimulate cells to produce survival factors, making the cell viability higher than the blank group. Mouse eosinophils, macrophages and monocytes have all been shown to secrete survival factors to enhance plasma cell activity (Belnoue et al. 2012, Chu et al. 2011, Winter et al. 2010). It can be speculated that the same mechanism occurs in coelomocytes. While the exposure concentration of 2Pentanone and 2-Hexanone is higher than $1 \mathrm{mM}$, a significant inhibitory effect was exerted, which reducing the cell viability.

\subsubsection{Changes in intracellular ROS levels}

The intracellular esterase can hydrolyze the DCFH-DA that has penetrated into the cell to DCFH carboxylic anion and remain in the cell. ROS can oxidize DCFH-DA carboxylate anion to 2,7-dichlorofluorescein which can be detected with high fluorescence (Eruslanov \&Kusmartsev 2010, Kalyanaraman et al. 2012). According to Fig. 2(b), the ROS content shows a trend of substantial increase with the exposure of 2Pentanone and 2-Hexanone. Specifically, when the concentration of 2-Pentanone and 2-Hexanone was $0.1 \mathrm{mM}$, the relative content of ROS was $174.27 \%$ and $81.75 \%$, respectively. However, the above values expanded to $729.64 \%$ and $607.84 \%$ when the exposure concentration increased to $10 \mathrm{mM}$. The results show that both 2-Pentanone and 2-Hexanone can cause cells to produce a large amount of ROS, and the continuous increase of ROS level can lead to oxidation of the intracellular environment. ROS plays an irreplaceable role in intracellular signal transduction, and its imbalance can disrupt the expression of genes activated by redox mechanisms (Ruiz-Ramos et al. 2009). That 2-Pentanone and 2-Hexanone induce excessive ROS in coelomocytes may be one of the mechanisms that cause cytotoxicity. Excessive ROS may destroy intracellular calcium homeostasis (Liu et al. 2017, Xu et al. 2019a) and induce lipid peroxidation, eventually leading to cell death.

\subsubsection{Exploring the activity of antioxidants (SOD, CAT and GSH)}

The antioxidant system consists of antioxidant enzymes and a variety of non-enzymatic substances. Among them, SOD and CAT are direct antioxidant enzymes that play an important role in maintaining redox homeostasis. The non-enzymatic substances that bear the antioxidant effect mainly include GSH, pyruvate, flavonoids and carotenoids. The level of SOD, CAT and GSH in coelomocytes exposed to different concentrations of ligands were measured to evaluate whether the antioxidant defense system is involved in the cytotoxicity and oxidative stress induced by 2-Pentanone and 2-Hexanone. 
In Fig. 3(a), under the exposure of 2-Pentanone and 2-Hexanone, the SOD activity showed a decreasing trend in general. When the concentration of 2-Pentanone and 2-Hexanone reached to $10 \mathrm{mM}$, the SOD activity was down to $76.50 \%$ and $89.18 \%$, respectively, indicating that the oxidative damage was occurred and oxidative system was damaged in the cells. The exposure of high concentration 2-Pentanone and 2Hexanone induced more ROS than antioxidant enzymes could handle, causing a part of SOD to be oxidized, thereby reducing its activity.

As shown in Fig. 3(b), as the concentration of 2-Pentanone and 2-Hexanone increase, CAT activity shows a trend of first increasing and then decreasing. When coelomocytes were exposed to a lower concentration of ligands (0-5 mM), the intracellular CAT activity exhibited a "bell-shaped" effect (Wang et al. 2017a). Specifically, when the concentration of 2-Pentanone and 2-Hexanone were both $1 \mathrm{mM}$, the CAT activity reached to the peak values, which were $105.19 \%$ and $130.98 \%$, respectively. This result can be explained from two aspects: on the one hand, the phenomenon shows that the exposure of 2Pentanone and 2-Hexanone can induce "hormetic response" of enzymatic systems (Hashmi et al. 2014). On the other hand, the increase in CAT activity under low-concentration toxicant exposure is the result of the direct antioxidant enzyme's adaptation to oxidative stress (Xu et al. 2019a), which is to remove excess $\mathrm{H}_{2} \mathrm{O}_{2}$ induced by ROS in the cell. When the concentration of 2-Pentanone and 2-Hexanone reached to $10 \mathrm{mM}$, the activity of CAT was inhibited and decreased to $78.11 \%$ and $87.04 \%$, respectively. The results can be attributed to the excessive $\mathrm{H}_{2} \mathrm{O}_{2}$ generated by exposure to high concentration of pollutants that exceeded the processing capacity of CAT.

As shown in Fig. 3(c), the GSH activity showed a trend of first decreasing and then increasing as the exposure concentration of 2-Pentanone and 2-Hexanone. Under low exposure concentration (0-1 mM), the GSH level kept decreasing trend, with the lowest values being $43.31 \%$ and $16.66 \%$, respectively. It can be speculated that the decrease of GSH level was owed to the non-enzymatic substances in the antioxidant system have poor antioxidant capacity in the early stage and fail to produce a large amount of GSH, which led to the continuous consumption of GSH in the fight against a large number of oxygencontaining free radicals. It is worth noting that at high exposure concentration (1-10 mM), the intracellular GSH activity continued to increase, and the maximum GSH values corresponding to 2Pentanone and 2 -Hexanone were $145.90 \%$ and $101.62 \%$, respectively. The results indicate that nonenzymatic antioxidants have adapted to intracellular oxidative damage.

\subsubsection{Determination of MDA and T-AOC level}

Lipid peroxidation is considered to be a major mechanism of cytotoxicity (Teng \&Liu 2013). Once the intracellular redox balance is disrupted, the excess ROS will attack the lipid components in the body, including phospholipids, enzymes and receptor proteins on the oxidized biofilm, and form lipid peroxidation products, causing oxidative damage (Reed 2011). As an important biomarker, the level of MDA is often used to evaluate the degree of oxidative stress and damage in cells. As shown in Fig. 4(a), with the exposure of 2-Pentanone, the intracellular MDA level continued to rise to $148.12 \%$. For 2Hexanone, as the exposure concentration of 2-hexanone increased, the MDA level increased slightly, 
eventually reaching to $106.29 \%$. Under the higher concentration exposure, more and more ROS were produced, which could not be eliminated by the antioxidant system, so the lipid peroxidation level of coelomocytes gradually increased.

As shown in the Fig. 4(b), the antioxidant capacity of coelomocytes first increased and then decreased as the exposure concentration of 2-Pentanone and 2-Hexanone increased. Under low exposure concentration (0-1 mM), the highest level of antioxidant capacity caused by 2-Pentanone and 2-Hexanone were $192.91 \%$ and $134.31 \%$, respectively. As the exposure concentration increased, the antioxidant capacity was significantly inhibited, which led the antioxidant level decreased to $42.22 \%$ and $12.54 \%$. Through direct antioxidant enzyme activity determination, when exposed to low concentrations, the cells have high direct antioxidant enzyme activity, so they have more powerful antioxidant capacity. Otherwise, the opposite is true.

\subsection{Effects of 2-Pentanone and 2-Hexanone on CAT 3.2.1. Investigation of fluorescence quenching mechanism of CAT}

Fluorescence spectrometry is often utilized to evaluate the changes in microenvironment of amino acids and the quenching mechanism between proteins and ligands (Cheng et al. 2013, Zhao et al. 2015). Preliminary experiments on the absorbance of the two ligands showed that the sum of the absorption values of 2-Pentanone and 2-Hexanone at $280 \mathrm{~nm}$ (excitation wavelength) and $334 \mathrm{~nm}$ (emission wavelength) were both greater than 0.05 , and the error caused by the inner filter effect (IFE) will exceed $5 \%$, so the IFE cannot be ignored in this system (Lakowicz 2006, Zhao et al. 2011). After using the Eq. (2) to correct fluorescence intensity, the fluorescence spectrums of CAT under the action of 2-Pentanone and 2-Hexanone are shown in Fig. 5(a), (b). After CAT was exposed to the ligands, the fluorescence intensity decreased regularly, indicating that the ligands interacted with amino acid residues (Trp, Tyr and Phe) (Lakowicz \&Masters 1991). It is worth noting that there is no lateral shift of the absorption peak position, so under the action of 2-Pentanone and 2-Hexanone, the microenvironment of aromatic amino acid residues of CAT was not changed significantly (Yuan et al. 1998). This reaction mechanism quenched the endogenous fluorescence of CAT and resulted in the possibility of fluorescent residues contacting with 2Pentanone and 2-Hexanone (Zhao et al. 2019).

Fluorescence quenching mainly has two forms: static quenching and dynamic quenching (Cui et al. 2012). To determine the mechanism of fluorescence quenching of CAT, the time-resolved fluorescence spectroscopy was introduced to measure the fluorescence lifetime of CAT after exposure to different concentrations of ligands. The curve in Fig. S1 fitted the double exponential decay model. The average fluorescence lifetime of amino acid residues was calculated by Eq. (3). According to Table 1, under the increasing concentration of 2-Pentanone and 2-Hexanone, the average fluorescence lifetime values of CAT did not change significantly, proving that 2-Pentanone and 2-Hexanone induced static quenching of CAT fluorescence and interacted with CAT by forming a complex (Lakowicz 2006). 
Table 1

Fluorescence lifetime of CAT exposed to 2-Pentanone and 2-Hexanone

\begin{tabular}{|c|c|c|c|c|c|c|c|}
\hline \multirow[t]{2}{*}{ Molar ratio } & & \multicolumn{2}{|c|}{ Lifetime(ns) } & \multicolumn{2}{|c|}{ Amplitude(\%) } & \multirow[t]{2}{*}{$\tau_{A V}(n s)$} & \multirow[t]{2}{*}{$x^{2}$} \\
\hline & & $\tau_{1}$ & $\tau_{2}$ & $a_{1}$ & $a_{2}$ & & \\
\hline CAT/ & $1: 0$ & 1.5189 & 4.9797 & 38.44 & 61.56 & 3.649368 & 1.106 \\
\hline \multirow[t]{3}{*}{ 2-Pentanone } & $1: 100$ & 1.6172 & 5.0610 & 41.37 & 58.63 & 3.636300 & 1.054 \\
\hline & $1: 200$ & 1.5987 & 5.1745 & 41.95 & 58.05 & 3.674452 & 1.064 \\
\hline & $1: 500$ & 1.6052 & 5.1909 & 43.27 & 56.73 & 3.639368 & 0.929 \\
\hline CAT/ & $1: 100$ & 1.6854 & 5.3122 & 44.22 & 55.78 & 3.708429 & 0.939 \\
\hline \multirow[t]{2}{*}{ 2-Hexanone } & $1: 200$ & 1.6361 & 5.1807 & 41.60 & 58.40 & 3.706146 & 1.116 \\
\hline & $1: 500$ & 1.5724 & 5.0845 & 42.23 & 57.77 & 3.601340 & 1.029 \\
\hline
\end{tabular}

Synchronous fluorescence spectrum expresses the changes in the microenvironment of Tyr or Trp residues when $\Delta \lambda=15 \mathrm{~nm}$ or $60 \mathrm{~nm}$ (Khan et al. 2008, Patra et al. 2012). As can be seen in Fig. S2, under a short-term exposure to 2-Pentanone, the synchronous fluorescence spectrum of CAT showed a red shift (from $291.0 \mathrm{~nm}$ to $292.2 \mathrm{~nm}, \Delta \lambda=15 \mathrm{~nm}$ ), indicating that the combination of 2-Pentanone and CAT caused a slight change on Tyr residues microenvironment and reduced its hydrophobicity. On the contrary, the interaction with 2-Hexanone resulted in a weak blue shift (from $291.6 \mathrm{~nm}$ to $290.6 \mathrm{~nm}, \Delta \lambda=$ $15 \mathrm{~nm}$ ) of the synchronous fluorescence of CAT, which verified that the microenvironment of Tyr residues became more hydrophobic. According to Fig. 5(c) and (d), the two ligands have little effect on the hydrophilicity and hydrophobicity of Trp residues microenvironment $(\Delta \lambda=60 \mathrm{~nm})$. The synchronous fluorescence results is similar to the fluorescence spectrum, which verifies that Trp residues make most of the contribution to CAT fluorescence (Trp: Tyr: Phe =100: 9: 0.5) (Xu et al. 2019b). It is noteworthy that all of the results of synchronization and endogenous fluorescence spectrum can indicate that the hydrophobicity of the aromatic amino acid residues microenvironment of CAT has not been changed significantly.

\subsubsection{Structural changes of CAT induced by 2-Pentanone and 2-Hexanone}

The UV-Visible absorption spectroscopy can determine the changes of proteins conformation (Grante et al. 2014). As shown in Fig. 6, CAT has three UV-vis absorption peaks. Among them, the strongest one $(200-230 \mathrm{~nm})$ is the absorption peak of the CAT skeleton, which is caused by the $\pi-\pi^{\star}$ electronic transitions of the peptide backbone $\mathrm{C}=0$ (Teng \&Liu 2013). As the concentration of 2-Pentanone increased, the absorbance of CAT in the wavelength range of $200-230 \mathrm{~nm}$ increased significantly, accompanied by the blue shift of the maximum absorption peak. On the other hand, under the action of 
2-Hexanone, the skeleton absorption peak intensity of CAT increased with a blue shift followed by a slight red shift. The above phenomenon indicated that in the presence of ligands, the reaction system underwent a hyperchromic reaction, and the CAT skeleton structure was contracted. Absorption peaks located at 260-290 nm reflect the changes in the microenvironment of Trp, Tyr and Phe residues of aromatic amino acids (Wu et al. 2007). As the exposure of 2-Pentanone and 2-Hexanone deepens, the intensity of the absorption peak changed slightly, illustrating that the hydrophobicity of the aromatic amino acid microenvironment of CAT has not been significantly changed (Laurent \&Assfeld 2010, Xu et al. 2006). As the characteristic peak of Porphyrin-Soret band, the absorption peak at around $405 \mathrm{~nm}$ can reflect the conformational change of the polypeptide chain near heme groups of CAT (Bao et al. 2001, Wang et al. 2018). Heme groups lie in the center of CAT enzyme activity and participate in the catalytic reaction of CAT (Reid et al. 1981). Under 0-5 mM exposure of 2-Pentanone and 2-Hexanone, the corresponding absorption peak intensity increased, but there was no lateral movement, indicating that the interaction of 2-Pentanone and 2-Hexanone with CAT may have an impact on the enzyme activity but exert little impact on polypeptide chain structure near heme groups. Heme groups are deeply embedded $20 \AA$ below the surface of CAT (Reid et al. 1981). The above results suggest that because of steric hindrance, there is no direct interaction between ligands and amino acid residues surrounding the heme groups. (Zamocky et al. 1995).

\subsubsection{Secondary structure changes of CAT}

The changes in the secondary structure of CAT under the exposure of 2-Pentanone and 2-Hexanone were reflected by circular dichroism (CD) spectra (Lu et al. 2007, Tabassum et al. 2012). The $n-\pi^{\star}$ and $\pi-\pi^{*}$ transitions of a-helix are the reason for the presence of the two negative peaks around $209 \mathrm{~nm}$ and 219 $\mathrm{nm}$ in the CD spectrum of CAT (Li et al. 2015). Fig. S3 and Table. 2 show the CD spectra of CAT under different concentrations of ligands exposure and the changes of CAT secondary structure content obtained by CDPro analysis respectively. As shown in the Fig. S3, the negative peak signal of CD spectra strengthened, revealing that the content of CAT secondary structure a-helix increased under the action of the ligands. According to the information in Table 2, Under the exposures of 2-Pentanone and 2Hexanone, a-helix content increased from $19.4-22.6 \%$ and $22.2 \%$, respectively, while $\beta$-sheet showed a decreasing trend, from $31.1-27.4 \%$ and $29.4 \%$, manifesting that the ligands make CAT misfold and partially denature. Due to the specific correspondence between the structure of the proteins and physiological function, any structural changes may cause the loss of physiological function (Koshland 1963). Based on the results, it can be deduced that the enzymatic activity of CAT may have changed due to its structure. 
Table 2

Effects of 2-Pentanone and 2-Hexanone on the secondary structural contents of CAT

\begin{tabular}{|c|c|c|c|c|c|}
\hline & & & & & \\
\hline \multirow{2}{*}{\multicolumn{2}{|c|}{ Molar ratio }} & \multicolumn{4}{|c|}{ Secondary structural elements in CAT(\%) } \\
\hline & & \multirow{2}{*}{$\begin{array}{l}\text { a-helix } \\
19.4\end{array}$} & \multirow{2}{*}{$\begin{array}{l}\beta \text {-sheet } \\
31.1\end{array}$} & \multirow{2}{*}{$\begin{array}{l}\text { Turns } \\
20.9\end{array}$} & \multirow{2}{*}{$\begin{array}{l}\text { Unordered } \\
28.6\end{array}$} \\
\hline CAT/ & $1: 0$ & & & & \\
\hline 2-Pentanone & $1: 1000$ & 22.2 & 27.5 & 20.8 & 29.5 \\
\hline & $1: 10000$ & 22.6 & 27.4 & 20.7 & 29.3 \\
\hline CAT/ & $1: 1000$ & 20.4 & 30.2 & 20.7 & 28.7 \\
\hline 2-Hexanone & 1:10000 & 22.2 & 29.4 & 19.5 & 28.9 \\
\hline
\end{tabular}

\subsubsection{Evaluation of protein size changes}

The particle size of CAT before and after exposure of 2-Pentanone and 2-Hexanone were reflected by the resonance light scattering spectrum (RLS). The intensity of RLS is proportional to the volume of the system particles (Mandal \&Ganguly 2009, Wang et al. 2000). As shown in Fig. 7, with the increase of the concentration of 2-Pentanone and 2-Hexanone, the intensity of RLS showed a gradually increasing trend. So both 2-Pentanone and 2-Hexanone can interact with CAT to form the ligand-protein complexes with larger particle diameters. That is consistent with the result obtained by time fluorescence spectroscopy. By comparing with the group of pure CAT, the increase of the RLS intensity can also confirm that the combination of CAT with 2-Pentanone and 2-Hexanone changed the properties of the solvent shell on the protein surface (Chaturvedi et al. 2014), making the protein surface more viscous, and then enhancing the aggregation effect among CAT molecules and increasing the particle size of the system gradually.

\subsubsection{Detection of CAT activity}

Changes in protein structure are often closely related to functional expression (Lavery \&Sacquin-Mora 2007). It can be seen from the spectral results that under the action of 2-Pentanone and 2-Hexanone, the structure of CAT was significantly changed. To further verify whether the expression of CAT activity was affected, an enzyme activity experiment with $\mathrm{H}_{2} \mathrm{O}_{2}$ as a substrate was carried out. As shown in Fig. 8, CAT activity that maintained a continuous decreasing trend downed to $69.50 \%$ and $64.05 \%$ compared with the control group at the maximum exposure concentration of 2-Pentanone and 2-Hexanone. The decline of CAT enzyme function can be attributed to the contraction of CAT structure. Due to the binding of ligands, CAT protein structure was contracted, which narrowed the molecular channel extending from CAT surface to the heme group. So the substrate $\mathrm{H}_{2} \mathrm{O}_{2}$ could not smoothly pass through the molecular channel to bind to the active center of CAT (Reid et al. 1981, Wang et al. 2015).

\subsubsection{Binding model of 2-Pentanone and 2-Hexanone to CAT}


To further explore the binding modes of 2-Pentanone, 2-Hexanone and CAT, the molecular docking which can explain the changes of protein structure and activity was carried out with MOE software (Chemical Computing Group V2009, Canada) (Xu et al. 2019b). CAT is composed of four identical subunits (one of the subunits is shown in Fig. 9), and the heme group is located at the active site of the subunit. The docking structure at the lowest Gibbs Free Energy was obtained by molecular docking calculation. As shown in Fig. 9(a2) and (b1), both 2-Pentanone and 2-Hexanone bound to the surface of CAT and far away from the active site. This simulated structure proves that the change in CAT activity is not the result of the ligands acting directly on the active site. But the surface binding of ligands and CAT is the inducement of changes in CAT skeleton structure and secondary structure. The amino acid residues listed in Fig. 9(a1) and (b2) are related to the binding of CAT to 2-Pentanone and 2-Hexanone, respectively. The oxygen atoms in 2-Pentanone and 2-Hexanone formed hydrogen bond structures with the Ser and Asp residues in CAT with bond lengths of $2.82 \AA$ and $2.55 \AA$, respectively.

\section{Conclusions}

This article reveals the toxic effects and mechanisms of 2-Pentanone and 2-Hexanone, which are commonly used in the industry, at the cellular and molecular level. The cell experiments showed that as the exposure of 2-Pentanone and 2-Hexanone, cell viability increased first and then decreased. A large amount of ROS produced by exposure gradually reduced the activity of intracellular antioxidant enzyme SOD and induced excessive $\mathrm{H}_{2} \mathrm{O}_{2}$. The antioxidant system had to secrete CAT to eliminate $\mathrm{H}_{2} \mathrm{O}_{2}$, which made the intracellular CAT activity present a "bell-shaped" effect. The oxidative stress induced by ROS ultimately increased the level of lipid peroxidation in coelomocytes, which indicates that the cell membrane has been damaged. The regular changes in total antioxidant capacity are also the result of oxidative damage of coelomocytes caused by exposure of 2-Pentanone and 2-Hexanone. Molecular level experiments show that the combination of 2-Pentanone and 2-Hexanone with CAT contracted the protein structure, which is related to the change in the secondary structure represented by the increase in a-helix content. The above-mentioned changes in protein structure are the reasons for the decline in CAT activity. Static quenching of CAT fluorescence further verified the occurrence of surface binding which has been revealed by molecular simulation. This study can provide systematic scientific data for exploring the cellular and molecular toxicity mechanisms of organic solvents commonly used in industry, and issue warnings for regulating the production, transportation and use of volatile solvents.

\section{Declarations}

\section{Acknowledgements}

We would like to thank Zhaozhen Cao from School of Chemistry and Chemical Engineering of Shandong University for help and guidance in circular dichroism spectroscopy experiment. 


\section{Ethics approval and consent to participate}

Not applicable.

\section{Consent for publication}

Not applicable.

\section{Authors contributions}

Xiangxiang Li: Conceptualization; Data curation; Formal analysis, Writing - original draft. Meifei Li: Methodology, Investigation, Formal analysis. Ning Sun: Conceptualization, Investigation. Falin He: Formal analysis, Writing - review \& editing, Shanshan Chu: Investigation. Wansong Zong: Software. Qigui Niu: Funding acquisition, Project administration. Rutao Liu: Conceptualization, Methodology, Writing - review \& editing.

\section{Funding}

This work was financially supported by NSFC $(21477067,21777088,21876103$, and U1806216), the Cultivation Fund of the Key Scientific and Technical Innovation Project, Research Fund for the Doctoral Program of Higher Education and Ministry of Education of China $(708058,20130131110016)$.

\section{Declaration of competing interest}

The authors declare that they have no conflict of interest.

\section{Availability of data and materials}

The data analyzed are available from the corresponding author on reasonable request.

\section{References}

Abdel-Rahman MS, Hetland LB, Couri D (1976) Toxicity and metabolism of methyl n-butyl ketone. Am Ind Hyg Assoc J 37:95-102. https://doi.org/10.1080/0002889768507418

Abdel-Rahman MS, Saladin JJ, Bohman CE, Couri D (1978) The effect of 2-hexanone and 2-hexanone metabolites on pupillomotor activity and growth. Am Ind Hyg Assoc J 39:94-99.

https://doi.org/10.1080/0002889778507722 
Arce A, Blanco A, Souza P, Vidal I (1995) Liquid-Liquid Equilibria of the Ternary Mixtures Water + Propanoic Acid + Methyl Ethyl Ketone and Water + Propanoic Acid + Methyl Propyl Ketone. J chem eng data 40:225-229. https://doi.org/10.1021/je00017a047

Bao X, Zhu Z, Li NQ, Chen J (2001) Electrochemical studies of rutin interacting with hemoglobin and determination of hemoglobin. Talanta 54:591-596. https://doi.org/10.1016/S0039-9140(00)00667-6

Belnoue E, Tougne C, Rochat AF, Lambert PH, Pinschewer DD, Siegrist CA (2012) Homing and adhesion patterns determine the cellular composition of the bone marrow plasma cell niche. J Immunol 188:12831291. https://doi.org/10.4049/jimmunol.1103169

Bianco A, Correa JM, Arce A, Correa A (1988) Liquid-liquid equilibria of the system water + acetic acid + methyl propyl ketone. Can J Chem Eng 66:136-140. https://doi.org/10.1002/cjce.5450660120

Brůhová Michalčíková R, Dryahina K, Španěl P (2016) SIFT-MS quantification of several breath biomarkers of inflammatory bowel disease, IBD: A detailed study of the ion chemistry. Int. J. Mass Spectrom 396:35-41. https://doi.org/10.1016/j.jjms.2015.12.007

Chaturvedi SK, Ahmad E, Khan JM, Alam P, Ishtikhar M, Khan RH (2014) Elucidating the interaction of limonene with bovine serum albumin: a multi-technique approach. Mol BioSyst 11:307-316. https://doi.org/10.1039/c4mb00548a

Chen Y, Lv R, Li L, Wang F (2017) Measurement and thermodynamic modeling of ternary (liquid+liquid) equilibrium for extraction of o-cresol, $\mathrm{m}$-cresol or $\mathrm{p}$-cresol from aqueous solution with 2-pentanone. J. Chem. Thermodyn 104:230-238. https://doi.org/10.1016/j.jct.2016.09.034

Cheng TN, Liang QY, Hande MP, Ong CN, Baeg GH (2017) Zinc oxide nanoparticles exhibit cytotoxicity and genotoxicity through oxidative stress responses in human lung fibroblasts and Drosophila melanogaster. Int J Nanomed 12:1621-1637. https://doi.org/10.2147/IJN.S124403

Cheng Z, Liu R, Jiang X (2013) Spectroscopic studies on the interaction between tetrandrine and two serum albumins by chemometrics methods. Spectrochim Acta, Part A 115:92-105. https://doi.org/10.1016/j.saa.2013.06.007

Chu VT, Fröhlich A, Steinhauser G, Scheel T, Roch T, Fillatreau S, Lee JJ, L?Hning M, Berek C (2011) Eosinophils are required for the maintenance of plasma cells in the bone marrow. Nat Immunol 12:151159. https://doi.org/10.1038/ni.1981

Couri D, Milks M (1982) Toxicity and Metabolism of the Neurotoxic Hexacarbons n-Hexane, 2-Hexanone, and 2,5-Hexanedione. Annu Rev Pharmacol 22:145-166. https://doi.org/10.1146/annurev.pa.22.040182.001045

Cui, F., Hui, G., Jiang, X., Zhang (2012) Interaction of 3'-azido-3'-deamino daunorubicin with DNA: Multispectroscopic and molecular modeling. Int J Biol Macromol 50:1121-1126. 
https://doi.org/10.1016/j.ijbiomac.2012.02.007

Czarna M, Jarmuszkiewicz W (2006) [Role of mitochondria in reactive oxygen species generation and removal; relevance to signaling and programmed cell death]. Postepy Biochem. 52:145-156.

Dick FD (2006) Solvent neurotoxicity. Occup Environ Med 63:221-226.

https://doi.org/10.1136/oem.2005.022400

El-Aal HAA (2012) Lipid Peroxidation End-Products as a Key of Oxidative Stress: Effect of Antioxidant on Their Production and Transfer of Free Radicals. InTech 63-88. https://doi.org/10.5772/45944

Eruslanov E, Kusmartsev S (2010) Identification of ROS Using Oxidized DCFDA and Flow-Cytometry. Methods Mol Biol 594:57-72. https://doi.org/10.1007/978-1-60761-411-1_4

Eyambe GS, Goven AJ, Fitzpatrick LC, Venables BJ, Cooper EL (1991) A non-invasive technique for sequential collection of earthworm (Lumbricus terrestris) leukocytes during subchronic immunotoxicity studies. Lab Anim 25:61-67. https://doi.org/10.1258/002367791780808095

Gao S, Jing M, Xu M, Han D, Niu Q, Liu R (2020) Cytotoxicity of perfluorodecanoic acid on mouse primary nephrocytes through oxidative stress: Combined analysis at cellular and molecular levels. $\mathrm{J}$ Hazard Mater 393:122444. https://doi.org/10.1016/j.jhazmat.2020.122444

Gopas J, Abd El Qader A, Isaacson C, Eichler D, Zeiri Y (2018) Urine volatile organic compounds composition in mice bearing breast and melanoma tumors: effect of low-protein diet. Curr. Biomarker Find 8:1-13. https://doi.org/10.2147/CBF.S160340

Grante I, Actins A, Orola L (2014) Protonation effects on the UV/Vis absorption spectra of imatinib: A theoretical and experimental study. Spectrochim Acta, Part A 129:326-332.

https://doi.org/10.1016/j.saa.2014.03.059

Hao M, Liu R (2019) Molecular mechanism of CAT and SOD activity change under MPA-CdTe quantum dots induced oxidative stress in the mouse primary hepatocytes. Spectrochim Acta, Part A 220:117104. https://doi.org/10.1016/j.saa.2019.05.009

Hashemi S, Ghotbi C, Taghikhani V, Behzadi B (2004) Application of quasi-chemical models to liquidliquid equilibrium calculations for ternary systems containing water, propionic acid and organic solvents. Fluid Phase Equilib 226:251-259. https://doi.org/10.1016/j.fluid.2004.07.007

Hashmi MZ, Naveedullah, Shen H, Zhu S, Yu C, Shen C (2014) Growth, bioluminescence and shoal behavior hormetic responses to inorganic and/or organic chemicals: A review. Environ Int 64:28-39. https://doi.org/10.1016/j.envint.2013.11.018

Hewitt WR, Miyajima H, Cté MG, Plaa GL (1980) Acute alteration of chloroform-induced hepato- and nephrotoxicity by $\mathrm{n}$-hexane, methyl $\mathrm{n}$-butyl ketone, and 2,5-hexanedione. Toxicol Appl Pharmacol 53:230- 
248. https://doi.org/10.1016/0041-008X(80)90423-8

Hewitt WR, Brown EM, Plaa GL (1983) Relationship between the carbon skeleton length of ketonic solvents and potentiation of chloroform-induced hepatotoxicity in rats. Toxicol Lett 16:297-304. https://doi.org/10.1016/0378-4274(83)90190-X

Jing M, Han G, Wan J, Zhang S, Yang J, Zong W, Niu Q, Liu R (2020) Catalase and superoxide dismutase response and the underlying molecular mechanism for naphthalene. Sci Total Environ 736: 139567. https://doi.org/10.1016/j.scitotenv.2020.139567

Kalyanaraman B, Darley-Usmar V, Davies KJA, Dennery PA, Forman HJ, Grisham MB, Mann GE, Moore K, li LJR, Ischiropoulos H (2012) Measuring reactive oxygen and nitrogen species with fluorescent probes: challenges and limitations. Free Radical Biol Med 52:1-6. https://doi.org/10.1016/j.freeradbiomed.2011.09.030

Kelce WR, Raisbeck MF, Ganjam VK (1990) Gonadotoxic Effects of 2-Hexanone and 1,2-Dibromo-3Chloropropane on the Enzymatic-Activity of Rat Testicular 17-Alpha-Hydroxylase C17,20-Lyase. Toxicol Lett 52:331-338. https://doi.org/10.1016/0378-4274(90)90043-L

Khan SN, Islam B, Yennamalli R, Sultan A, Subbarao N, Khan AU (2008) Interaction of mitoxantrone with human serum albumin: Spectroscopic and molecular modeling studies. Eur J Pharm Sci 35:371-382. https://doi.org/10.1016/j.ejps.2008.07.010

Koshland DE (1963) Correlation of Structure an Function in Enzyme Action Science 142:1533-1541. https://doi.org/10.1126/science.142.3599.1533

Lakowicz JR, Masters BR (1991) Principles of Fluorescence Spectroscopy, Third Edition. D Die Naturwissenschaften 78: p.456.

Lakowicz JR (2006) Principles of fluorescence spectroscopy. Springer, New York, 2006.

Laurent AD, Assfeld X (2010) Effect of the Enhanced Cyan Fluorescent Protein Framework on the UV/Visible Absorption Spectra of Some Chromophores. Interdiplinary ences Computational Life ences 2:38-47

Lavery R, Sacquin-Mora S (2007) Protein mechanics: a route from structure to function. J Biosci 32:891898. https://doi.org/10.1007/s12038-007-0089-x

Li S, Peng Z, Leblanc RM (2015) Method To Determine Protein Concentration in the Protein-Nanoparticle Conjugates Aqueous Solution Using Circular Dichroism Spectroscopy Anal Chem 87:6455-6459. https://doi.org/10.1021/acs.analchem.5b01451

Liu L, Chang X, Zhang Y, Wu C, Li R, Tang L, Zhou Z (2017) Fluorochloridone induces primary cultured Sertoli cells apoptosis: Involvement of ROS and intracellular calcium ions-mediated ERK1/2 activation. 
Toxicol. In Vitro 47:228-237. https://doi.org/10.1016/j.tiv.2017.12.006

Lu JQ, Jin F, Sun TQ, Zhou XW (2007) Multi-spectroscopic study on interaction of bovine serum albumin with lomefloxacin-copper(II) complex. Int J Biol Macromol 40:299-304.

https://doi.org/10.1016/j.ijbiomac.2006.08.010

Mandal P, Ganguly T (2009) Fluorescence spectroscopic characterization of the interaction of human adult hemoglobin and two isatins, 1-methylisatin and 1-phenylisatin: a comparative study. J Phys Chem B 113:14904-14913. https://doi.org/10.1021/jp9062115

Mochalski P, Leja M, Gasenko E, Skapars R, Santare D, Sivins A, Aronsson DE, Ager C, Jaeschke C, Shani G, Mitrovics J, Mayhew CA, Haick H (2018) Ex vivo emission of volatile organic compounds from gastric cancer and non-cancerous tissue. J Breath Res 12:046005. https://doi.org/10.1088/1752-7163/aacbfb

Nakajima T, Elovaara E, Park SS, Gelboin HV, Vainio H (1991) Immunochemical detection of cytochrome P450 isozymes induced in rat liver byn-hexane, 2-hexanone and acetonyl acetone. Arch Toxicol 65:542547. https://doi.org/10.1007/BF01973714

Patra D, Barakat C, Tafech RM (2012) Study on effect of lipophilic curcumin on sub-domain IIA site of human serum albumin during unfolded and refolded states: A synchronous fluorescence spectroscopic study. Colloids Surf, B 94:354-361. https://doi.org/10.1016/j.colsurfb.2012.02.017

Pedersen JE, Strandberg-Larsen K, Andersson M, Hansen J (2020) Occupational exposure to specific organic solvents and risk of subtypes of breast cancer in a large population of Danish women, 19642016. Occup Environ Med:oemed-2020-106865. https://doi.org/10.1136/oemed-2020-106865

Pettersson J, Karlsson PC, GÖRANSSON U, Rafter JJ, Bohlin L (2008) The flavouring phytochemical 2pentanone reduces prostaglandin production and COX-2 expression in colon cancer cells. Biol Pharm Bull 31:534-537. https://doi.org/10.1248/bpb.31.534

Rafaela G, Barros L, Barreira JOCM, Sousa MJO, Carvalho AM, Ferreira ICFR (2010) Targeting excessive free radicals with peels and juices of citrus fruits: Grapefruit, lemon, lime and orange. Food Chem Toxicol 48:99-106. https://doi.org/10.1016/j.fct.2009.09.022

Reed TT (2011) Lipid peroxidation and neurodegenerative disease. Free Radical Biol Med 51:1302-1319. https://doi.org/10.1016/j.freeradbiomed.2011.06.027

Reid, T., J., Murthy, M., R., Sicignano, A., Tanaka, N. (1981) Structure and heme environment of beef liver catalase at 2.5 A resolution. Natl Acad Sci U. S. A 78:4767-4771.

https://doi.org/10.1107/S0108767381098735

Ruiz-Ramos R, Lopez-Carrillo L, Rios-Perez AD, Vizcaya-Ruíz AD, Cebrian ME (2009) Sodium arsenite induces ROS generation, DNA oxidative damage, $\mathrm{HO}-1$ and c-Myc proteins, NF-kappaB activation and cell 
proliferation in human breast cancer MCF-7 cells. Environ Mutagen 674:109-115. https://doi.org/10.1016/j.mrgentox.2008.09.021

Santos PM, Del Nogal Sanchez M, Pozas APC, Pavon JLP, Cordero BM (2017) Determination of ketones and ethyl acetate-a preliminary study for the discrimination of patients with lung cancer. Anal Bioanal Chem 409:5689-5696. https://doi.org/10.1007/s00216-017-0508-2

Seidel CAM, Schulz A, Sauer MHM (1996) Nucleobase-specific quenching of fluorescent dyes .1. Nucleobase one-electron redox potentials and their correlation with static and dynamic quenching efficiencies. J Phys Chem 100:5541-5553. https://doi.org/10.1021/jp951507c

Shukla RK, Kumar A, Vallabani NVS, Pandey AK, Dhawan A (2014) Titanium dioxide nanoparticle-induced oxidative stress triggers DNA damage and hepatic injury in mice. Nanomedicine 9:1423-1434. https://doi.org/10.2217/nnm.13.100

Sun H, Yang B, Cui E, Liu R (2014) Spectroscopic investigations on the effect of N-Acetyl-I-cysteineCapped CdTe Quantum Dots on catalase. Spectrochim Acta, Part A 132:692-699. https://doi.org/10.1016/j.saa.2014.04.157

Sun K, Song Y, Zong W, Tang J, Liu R (2020) Anthracene-induced DNA damage and oxidative stress: a combined study at molecular and cellular levels. Environ Sci Pollut Res Int 27:41458-41474. https://doi.org/10.1007/s11356-020-10049-y

Sur SS, Rabbani LD, Libman L, Breslow E (1979) Fluorescence Studies of Native and Modified Neurophysins - Effects of Peptides and Ph. Biochemistry 18:1026-1036.

https://doi.org/10.1021/bi00573a015

Tabassum S, Al-Asbahy WM, Afzal M, Arjmand F, Khan RH (2012) Interaction and photo-induced cleavage studies of a copper based chemotherapeutic drug with human serum albumin: spectroscopic and molecular docking study. Mol BioSyst 8:2424-2433. https://doi.org/10.1039/c2mb25119a

Teng Y, Liu R (2013) Insights into potentially toxic effects of 4-aminoantipyrine on the antioxidant enzyme copper-zinc superoxide dismutase. J Hazard. Mater 262:318-324. https://doi.org/10.1016/j.jhazmat.2013.08.047

Wang J, Zhang H, Zhang T, Zhang R, Liu R, Chen Y (2015) Molecular mechanism on cadmium-induced activity changes of catalase and superoxide dismutase. Int J Biol Macromol 77:59-67. https://doi.org/10.1002/jbt.22248

Wang J, Wang J, Zhang L, Liu R, Zong W (2017a) Response of Catalase of the Mouse Primary Hepatocytes to Sodium Dodecylbenzenesulfonate and the Underlying Molecular Mechanisms. J Agric Food Chem 65:3039-3047. https://doi.org/10.1021/acs.jafc.7b00291 
Wang J, Jia R, Wang J, Sun Z, Wu Z, Liu R, Zong W (2018) Investigation on the interaction of catalase with sodium lauryl sulfonate and the underlying mechanisms. J Biochem Mol Toxicol 32: e22025. https://doi.org/10.1002/jbt.22025

Wang J, Zheng X, Wang W, Guo H, Zong W (2019) A study on the interaction between cadmium and achymotrypsin and the underlying mechanisms. J Biochem Mol Toxicol 33:e22248.

https://doi.org/10.1002/jbt.22248

Wang M, Yang J, Wu X, Huang F (2000) Study of the interaction of nucleic acids with acridine red and CTMAB by a resonance light scattering technique and determination of nucleic acids at nanogram levels. Anal Chim Acta 422:151-158. https://doi.org/10.1016/S0003-2670(00)01041-2

Wang M, Xie R, Jia X, Liu R (2017b) Urinary Volatile Organic Compounds as Potential Biomarkers in Idiopathic Membranous Nephropathy. Med Princ Pract 26:375-380. https://doi.org/10.1159/000478782

Winter O, Moser K, Mohr E, Zotos D, Manz RA (2010) Megakaryocytes constitute a functional component of a plasma cell niche in the bone marrow. Blood 116:1867-1875. https://doi.org/10.1182/blood-2009-12259457

Wu T, Wu Q, Guan S, Su H, Cai Z (2007) Binding of the Environmental Pollutant Naphthol to Bovine Serum Albumin. Biomacromolecules 8:1899-1906. https://doi.org/10.1021/bm061189v

Xu M, Wan J, Niu Q, Liu R (2019a): PFOA and PFOS interact with superoxide dismutase and induce cytotoxicity in mouse primary hepatocytes: A combined cellular and molecular methods. Environ Res 175:63-70. https://doi.org/10.1016/j.envres.2019.05.008

Xu M, Zhang T, Lv C, Niu Q, Zong W, Tang J, Liu R (2019b) Perfluorodecanoic acid-induced oxidative stress and DNA damage investigated at the cellular and molecular levels. Ecotoxicol. Environ Saf 185:109699. https://doi.org/10.1016/j.ecoenv.2019.109699

Xu TW, Xu JH, Yu W, Zhong JH (2006) Investigating pH and Cu (II) effects on lipase activity and enantioselectivity via kinetic and spectroscopic methods. Biotechnol J 1:1293-1301. https://doi.org/10.1002/biot.200600135

Yuan T, Weljie, M. A, Vogel HJ (1998) Tryptophan fluorescence quenching by methionine and selenomethionine residues of calmodulin: orientation of peptide and protein binding. Biochemistry 37:3187-3195. https://doi.org/10.1021/bi9716579

Zamocky M, Herzog C, Nykyri LM, Koller F (1995) Site-directed mutagenesis of the lower parts of the major substrate channel of yeast catalase $A$ leads to highly increased peroxidatic activity. Febs Lett 367:241-245. https://doi.org/10.1016/0014-5793(95)00568-T

Zhao L, Song W, Wang J, Yan Y, Liu R (2015) Mechanism of Dimercaptosuccinic Acid Coated Superparamagnetic Iron Oxide Nanoparticles with Human Serum Albumin. J Biochem Mol Toxicol 
Zhao L, Guo D, Lin J, Liu R (2019) Responses of catalase and superoxide dismutase to low-dose quantum dots on molecular and cellular levels. Ecotoxicol. Environ Saf 181:388-394.

https://doi.org/10.1016/j.ecoenv.2019.06.028

Zhao X, Liu R, Teng Y, Liu X (2011) The interaction between Ag+ and bovine serum albumin: A spectroscopic investigation. Sci Total Environ 409:892-897.

https://doi.org/10.1016/j.scitotenv.2010.11.004

Zhao X, Lu D, Liu SQ, Li Y, Feng R, Hao F, Qu G, Zhou Q, Jiang G (2017) Hematological Effects of Gold Nanorods on Erythrocytes: Hemolysis and Hemoglobin Conformational and Functional Changes. Adv Sci 4:1700296. https://doi.org/10.1002/advs.201700296

Zimmermann FK, Scheel I, Resnick MA (1989) Induction of chromosome loss by mixtures of organic solvents including neurotoxins. Mutat Res, Genet Toxicol 224:287-303. https://doi.org/10.1016/01651218(89)90168-7

\section{Figures}

\section{Figures}

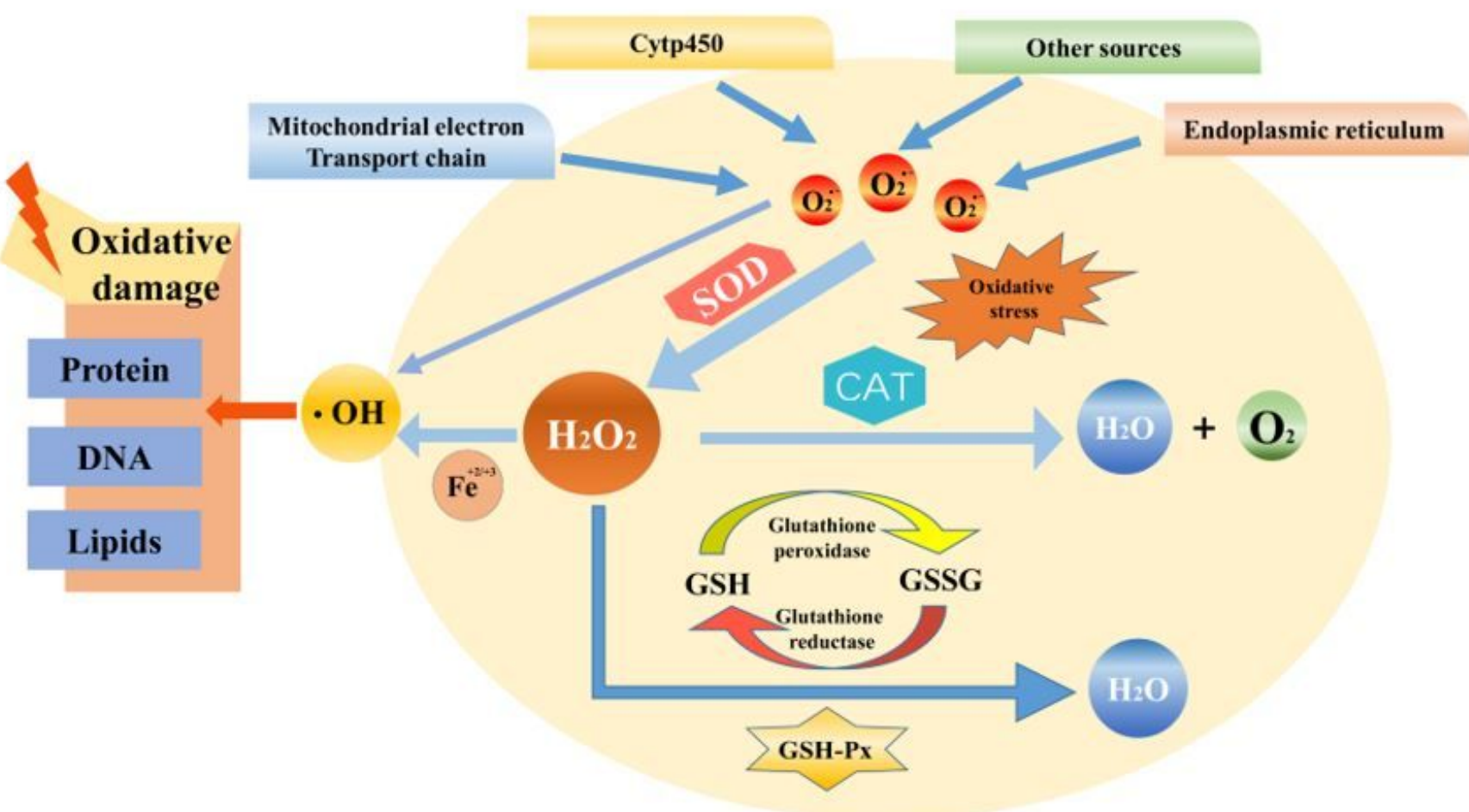

\section{The stimulus of adverse external conditions}



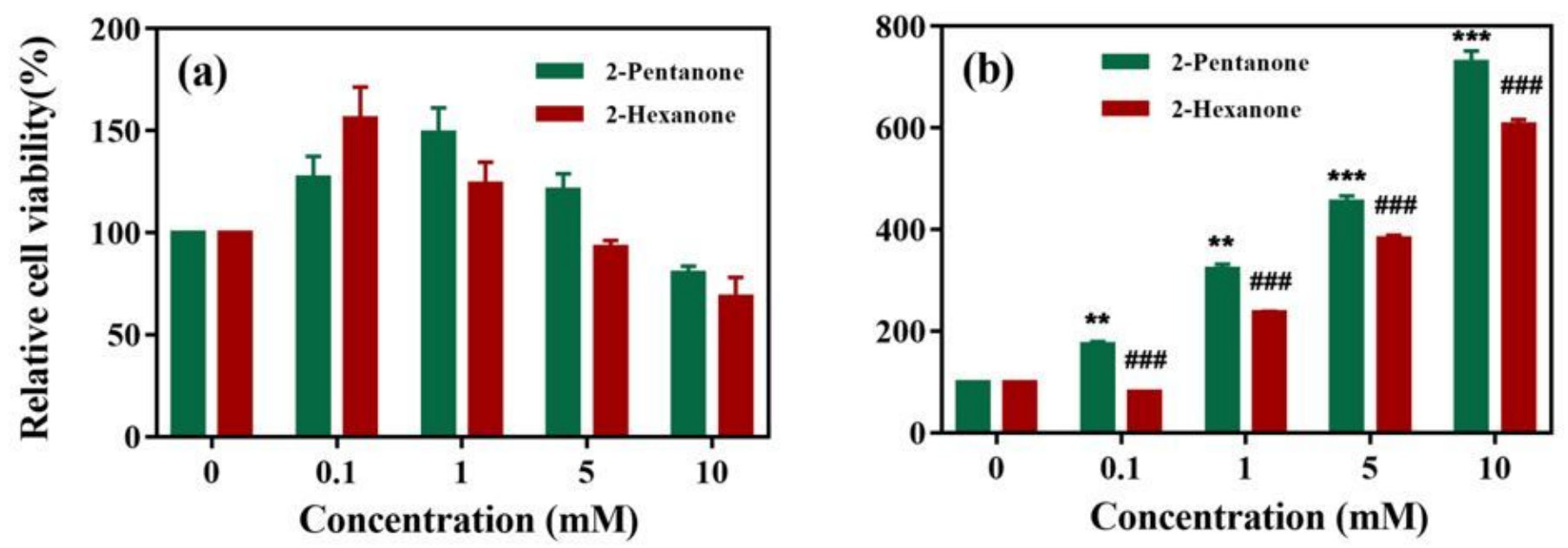

Figure 2

Viability changes (a) and ROS level (b) of coelomocytes induced by 2-Pentanone and 2-Hexanone for 24 h. Cells were exposed to 2-Pentanone or 2-Hexanone at gradients concentration: 0, 0.1, 1, 5, $10 \mathrm{mM}$ for 24 h. Values are shown as mean \pm SD of three independent experiments. Statistical differences from control group: *, \#p < 0.05, **, \#\#p $<0.01$ and ${ }^{* * *}, \# \# \# p<0.001$.
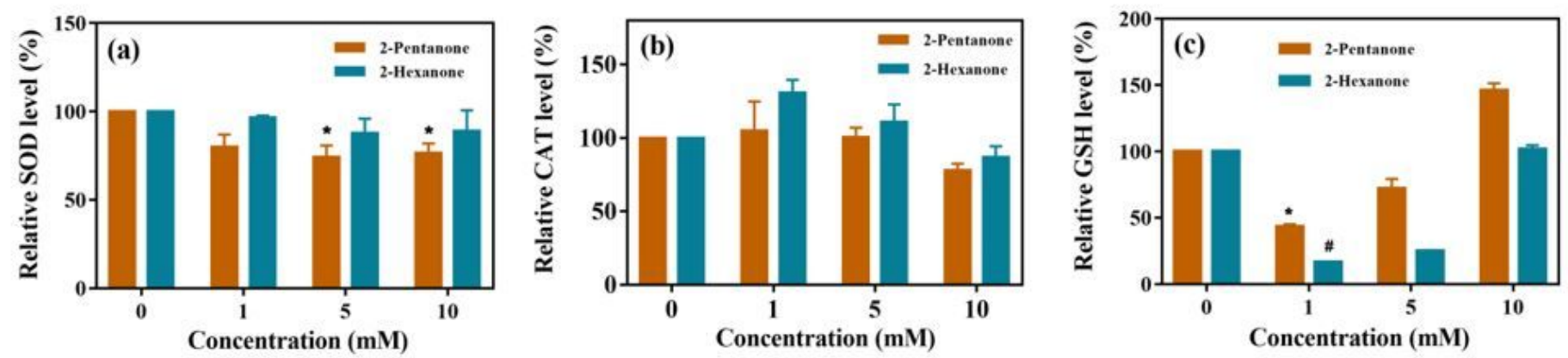

\section{Figure 3}

Relative SOD (a), CAT (b) and GSH level (c) in coelomocytes after exposing to 2-Pentanone and 2Hexanone for $24 \mathrm{~h}$. The pollutant concentration was set as follows: [2-Pentanone] or [2-Hexanone] $(\mathrm{mM})=$ $0,1,5,10$. Values are shown as mean \pm SD of three independent experiments. Compared with the control group, differences are considered statistically significant at *, \#p $<0.05, * *, \# \# p<0.01$ and ${ }^{* \star}$, \#\#\#p < 0.001 . 

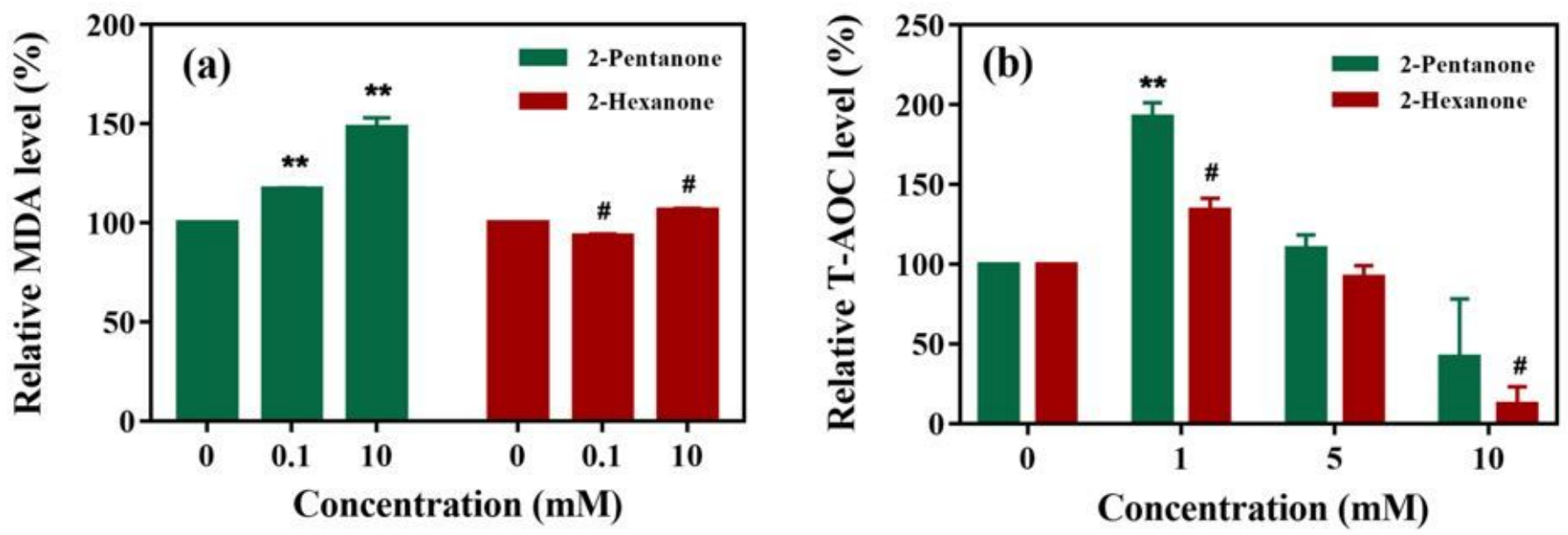

Figure 4

Relative MDA (a) and T-AOC level (b) in coelomocytes after exposing to 2-Pentanone and 2-Hexanone for $24 \mathrm{~h}$. Values are shown as mean \pm SD of three independent experiments. Compared with the control group, differences are considered statistically significant at $\# p<0.05, \star \star p<0.01$ and \#\#\#p<0.001.
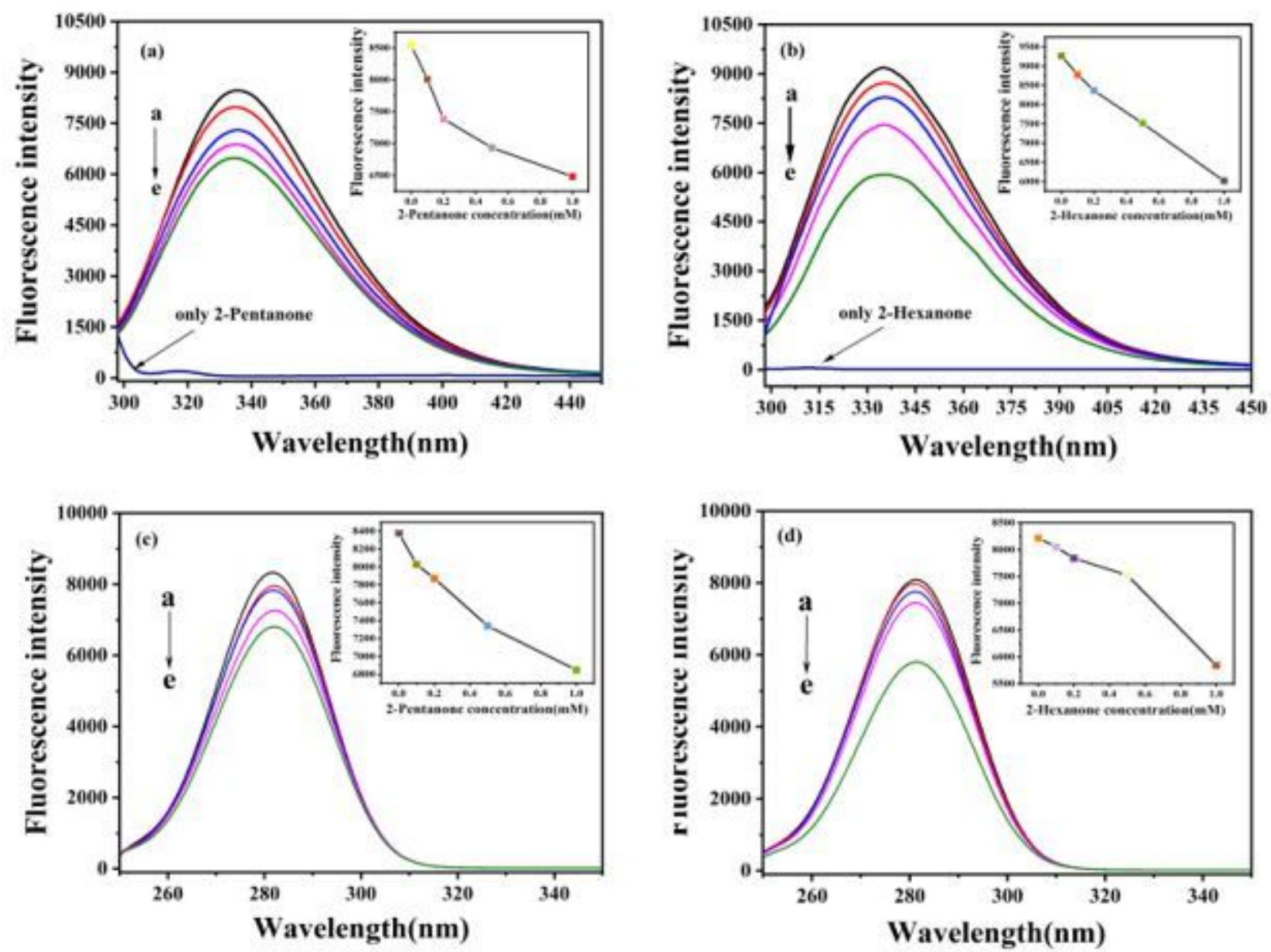
Figure 5

Endogenous fluorescence $(a, b)$ and synchronous fluorescence of Trp residues $(c, d)$ spectrum of CAT under 2-Pentanone and 2-Hexanone. Conditions: [CAT] $1 \mathrm{Mm}$; [2-Pentanone] (mM) or [2-Hexanone] mM) a-e: $0,0.1,0.2,0.5,1 ; \mathrm{pH}=7.4 ; \mathrm{T}=310 \mathrm{~K}$.
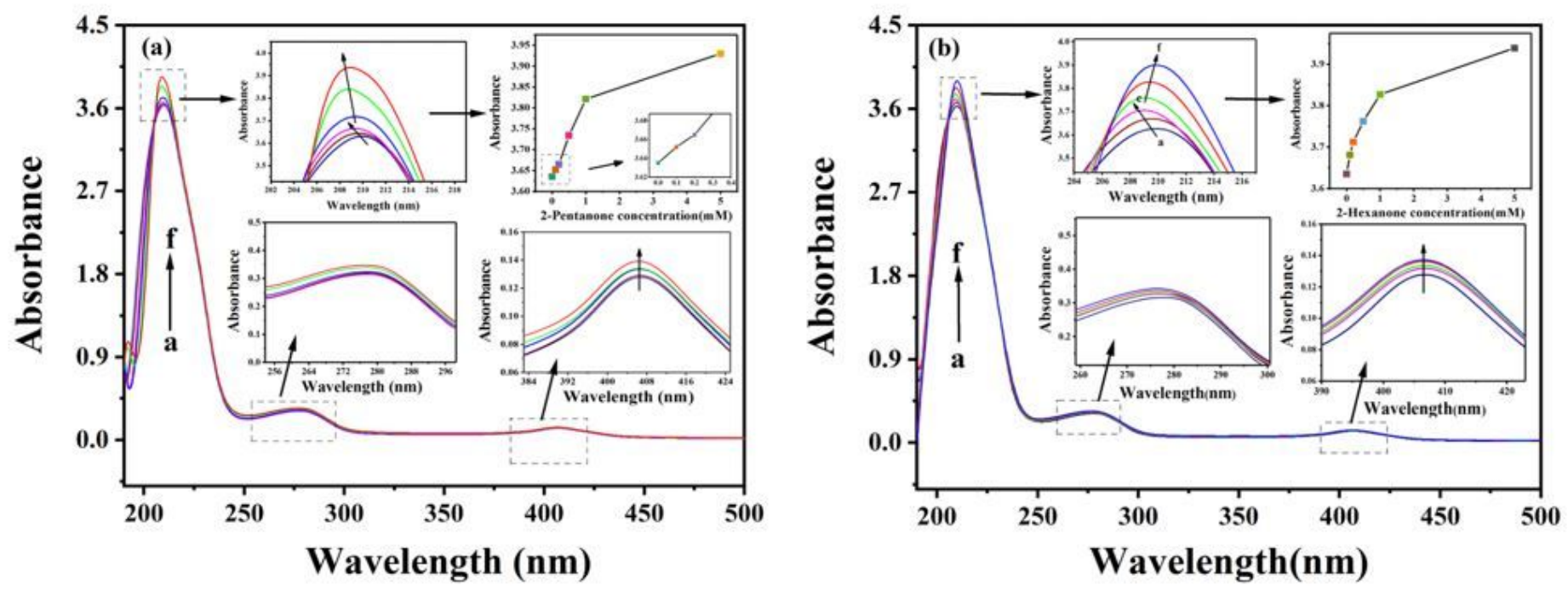

Figure 6

UV-vis absorption spectrum of CAT under exposure to 2-Pentanone (a) and 2-Hexanone (b). Conditions: [CAT] $1 \mu \mathrm{M}$; [2-Pentanone] (mM) a0-f0 or [2-Hexanone] (mM) a1-f1: 0, 0.1, 0.2, 0.5, 1, 5; pH = 7.4; T = 310 K.
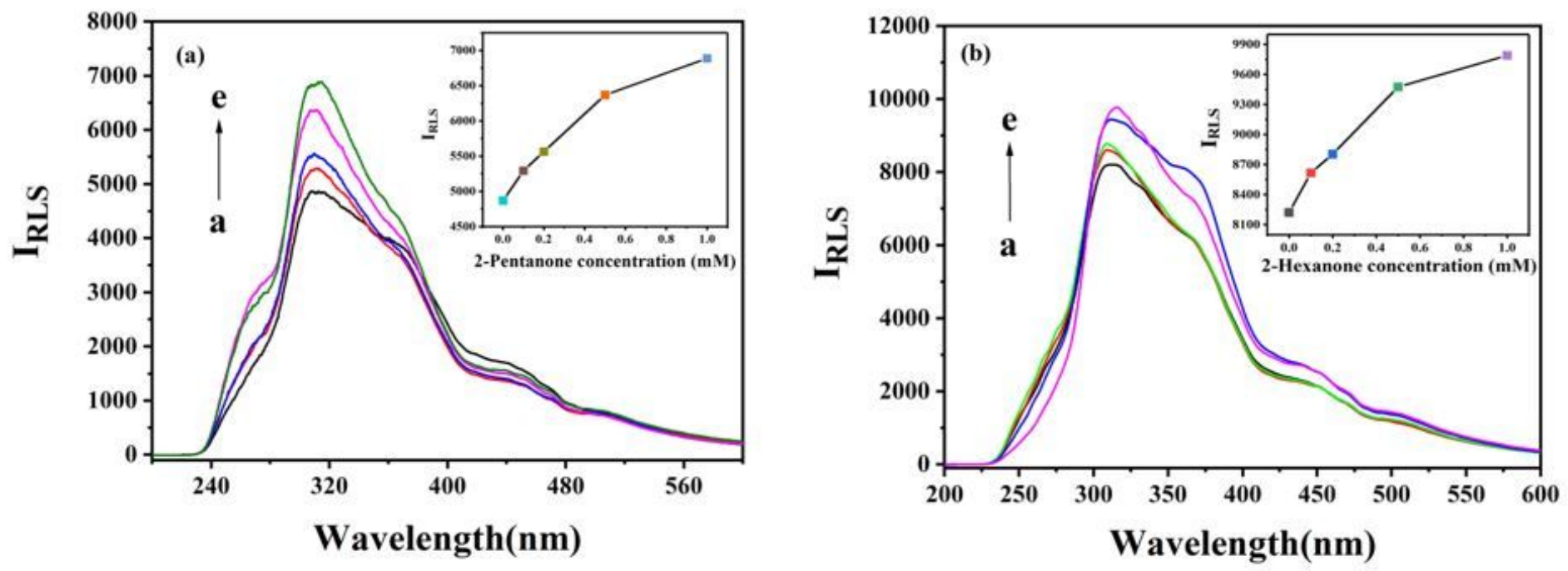

Figure 7 
The resonance spectrum of CAT under exposure of different concentration of 2-Pentanone (a) and 2Hexanone (b). Conditions: [CAT] $=1 \mu \mathrm{M}$; [2-Pentanone] or [2-Hexanone] $(\mathrm{mM})$ a-e: $0,0.1,0.2,0.5,1 ; \mathrm{pH}=$ $7.4 ; \mathrm{T}=310 \mathrm{~K}$.

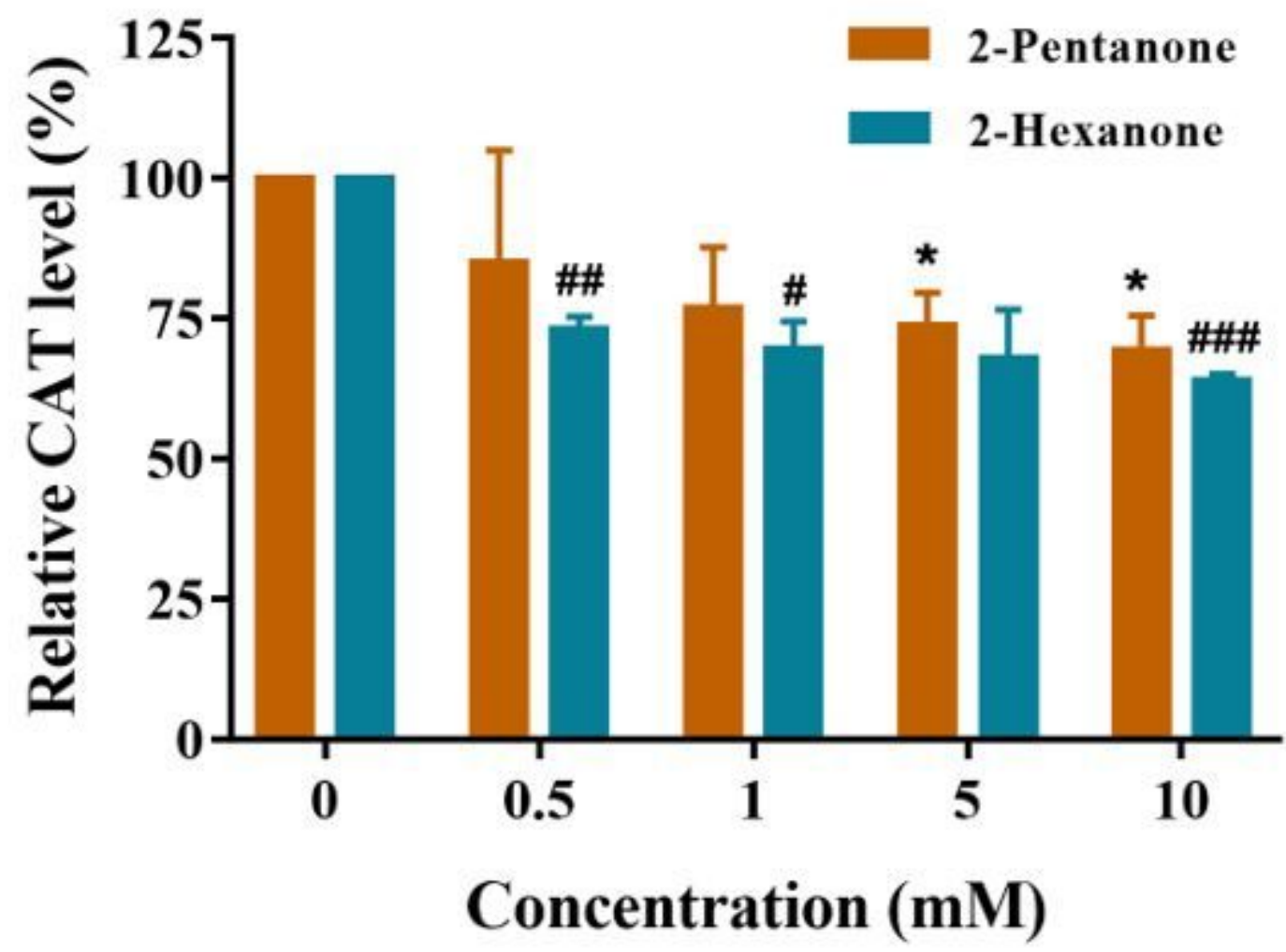

Figure 8

Activity changes of CAT under the exposure to 2-Pentanone and 2-Hexanone. Experimental conditions: [CAT] $=1 \mu \mathrm{M}$; [2-Pentanone] or [2-Hexanone] $(\mathrm{mM})$ a-e: 0, 0.5, 1, 5, 10; $\mathrm{pH}=7.4 ; \mathrm{T}=310 \mathrm{~K}$. Compared with the control group, differences are considered statistically significant at *, \#p $<0.05, * \star, \# \# p<0.01$ and ***, $\# \# \#$ < 0.001. 


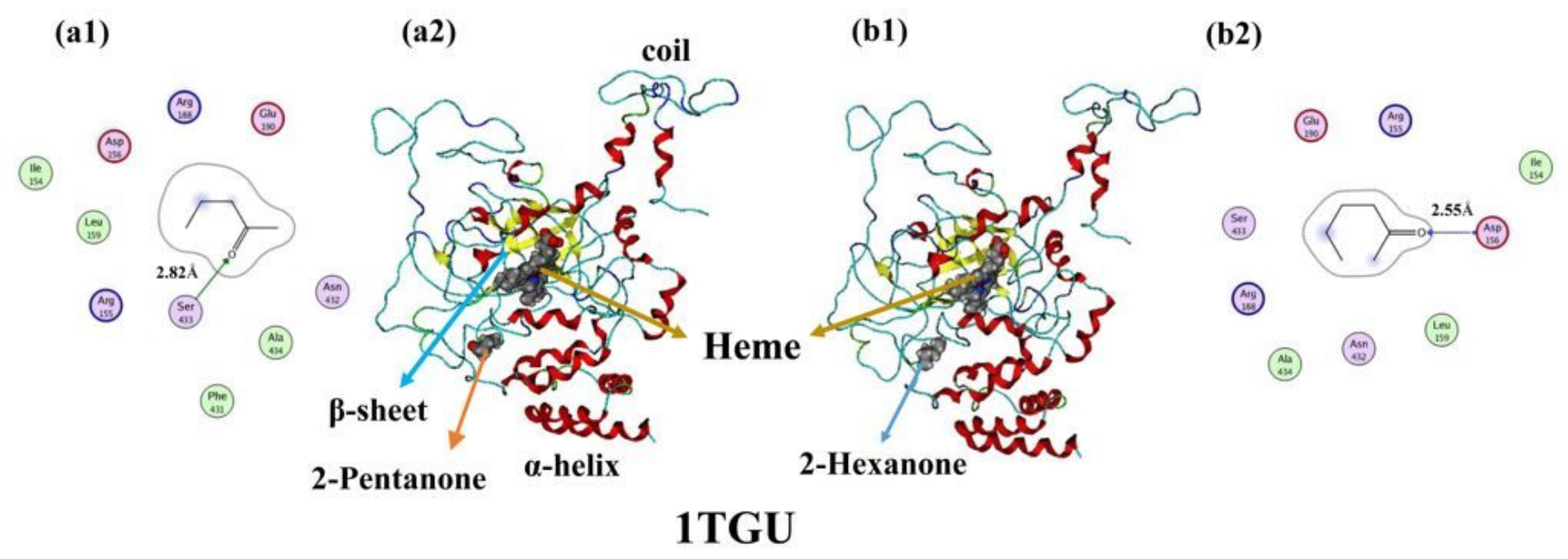

Figure 9

Binding interaction between CAT and 2-Pentanone (a) or 2-Hexanone (b). Experimental conditions: (a1) and (b2) show the combination of ligands and related amino acids residues of CAT; (a2) and (b1) reflect the binding sites of the ligands on the CAT. CAT molecule is shown in cartoon modes. the structure of CAT was downloaded from http://www.rcsb.org/ (PDB code 1TGU).

\section{Supplementary Files}

This is a list of supplementary files associated with this preprint. Click to download.

- SupplementaryMaterialforReview.docx 